\title{
Shuttle problems delay next planetary mission
}

\section{David Dickson reports from Washington on why Jupiter must wait}

The US National Aeronautics and Space Administration announced last week that it intends to delay the launch of Project Galileo - a two-vehicle mission to the planet Jupiter - from 1982 to 1984 because of problems in the development of the space shuttle.

The two-year delay will also mean separate launches for the two vehicles, one of which will orbit the planet, and the other descend into its atmosphere; initially plans were to use a single launch, but the delay means that the spacecraft will no longer be able to make use of extra push given by the planet Mars.

Dr Thomas Mutch, associate administrator for space science, told a House subcommittee in Washington last week that the agency had studied the implications of delays in developing the shuttle engines and decided that the risks involved in meeting the necessary schedules for both the shuttle and the inertial upper stage from which Galileo will be launched were "unacceptable". "The most costeffective and least-risk approach to retain the Galileo scientific objectives is to delay the launch until 1984, and launch the orbiter and the probe separately", Dr Mutch said.

The delay, and the need for a double launch, will mean a considerable increase in the cost of the project. Originally, with a 1982 launch, this was estimated at about $\$ 450$ million; the new estimate, including in particular the extra hardware which the double launch will require, is $\$ 675$ million.

Dr Mutch told Nature that the new plans, which will involve launching the orbiter several weeks ahead of the probe, will not effect the scientific programmes, and could indeed increase the quality of the results. "Since there will be a separate carrier devoted to the probe, we can now optimise its trajectory to get the maximum coordination with the orbiter," Dr Mutch said.

However the delay could mean further problems for the Galileo programme from Congress, which will have to give its approval to the new schedule and the increased cost. Two years ago, a bid to kill the project by Representative Edward Boland, chairman of NASA's appropriations subcommittee, was defeated on the floor of the House, only after a massive letter-writing campaign by the academic community.

This year, given the delays with the launch, the House accepted an amendment to NASA's appropriations bill proposed by Mr Boland which would give the subcommittee power to veto any move to split the mission. This has been rejected by the Senate, however, and negotiations are now taking place to find an adequate wording to

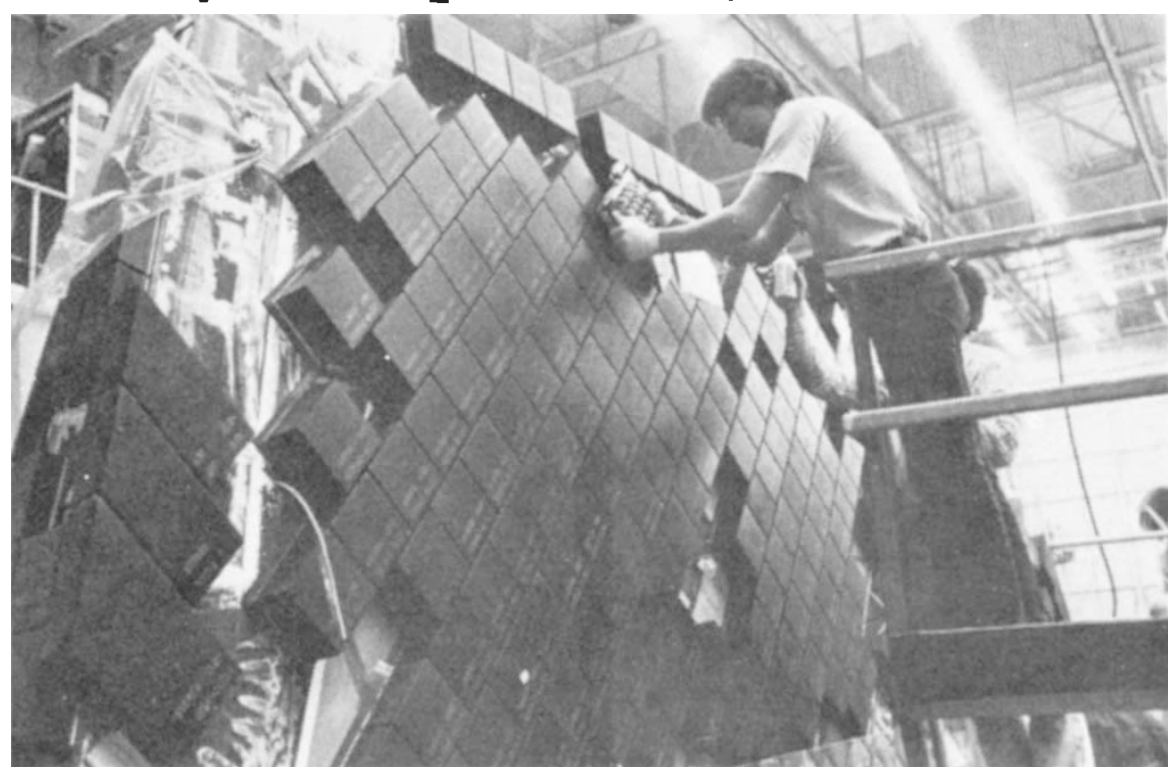

Sticky problem for the space shuttle; some of these protective tiles came off in flight

meet the House's concern for a review of the new plans, but without giving either legislative body veto powers.

NASA scientists are worried that Congress may try to reduce the costs by splitting the launch, and sending one half of the mission - possibly the orbiter - at a later date. They emphasise that NASA has no plans to split the mission in this way.

Meanwhile Dr Robert Frosch, administrator of NASA, told the House subcommittee that NASA calculated a 50-50 chance that the space shuttle would have its first flight by next summer. The flight was to have taken place this spring, but has been postponed after a series of technical problems. The most recent was replacing some of the thermal tiles, used to protect the re-usable shuttle when it reenters the earth's orbit, which came

\section{IQ tests 'unconstitutional'}

In what promises to be a landmark decision after a seven-year court battle, San Francisco's chief district court judge, Robert Peckham, has ruled that the use of standardised IQ tests to categorise children as mentally retarded discriminates against minorities and is thus unconstitutional.

The immediate effect will be to make permanent a state-wide injunction againsl these tests and to force state of ficials to re-evaluate black children previously identified as "educable mentally retarded"'.

The judge struck out at what he called the "grossly disproportionate enrolments of black children in the so-called "educable mentally retarded' classes". Although black children make up only $9 \%$ of the state school population, some $23 \%$ of the children enrolled in these classes are black. Not only is this unconstitutional, Judge Peckham ruled, but it violates federal civil unstuck during testing.

Admitting that this was a problem which "should have been clear sooner, but was not," Dr Frosch told the subcommittee that about $7 \%$ of the tiles so far tested had had to be replaced, implying a total of 2,400 out of the shuttle's 34,000 tiles.

Dr Frosch said that technical delays, in particular with the testing of engine performance, meant that the total cost of the shuttle development programme was now likely to be about $20 \%$ more than the initial estimate of $\$ 5.15$ billion at 1971 prices. He told the subcommittee that NASA had made a number of management changes after investigations to discover why the shuttle programme had run into problems at this stage. But he emphasised that a major factor had been serious underfunding of the programme early on. rights laws and statutes dealing with education for the handicapped as well. $\mathrm{He}$ ordered state officials to "monitor and eliminate" the disproportionate placements. The complex case was launched in 1971 by civil rights groups acting on behalf of six black children in San Francisco known only as Larry et al. The children had been placed in special classes because they had scored lower than 75 on $1 Q$ tests. When they were tested later by a group of black psychologists, their scores ranged from 17 to 38 points higher. State officials argued that the testing protocols and procedures used by the black psychologists violated accepted practice.

However, the case apparently was decided more on the basis of the general limitations of IQ tests rather than on the specific problems of these particular children. In testimony that ran for more than 10,000 pages, Peckham heard a wide 
range of arguments over the validity and proper use of IQ tests. Interestingly, neither side took a firm stand on the issue of whether or not "intelligence" as so measured represents an in-born ability. Rather, attorneys for the children argued that the tests are culturally biased, while the state argued that the tests remain good predictors of school performance for blacks as well as white.

The judge said that, in his opinion, "many black children have been isolated, stigmatised and provided with inadequate education on the basis of unwarranted and impermissible assumptions"'. The tests, he said, had not been modified or validated for blacks, while "almost no experts now contend that IQ measures innate intelligence",

Beyond the issue of the tests, themselves, Peckham found that the special classes are designed to provide only a "limited, deadend education for children who, while not severely retarded, are incapable of mastering the skills taught in a regular curriculum". Since placement is assumed to be permanent, he said, "the children assigned to those classes are unlikely ever to succeed in school, even if they are not truly retarded."

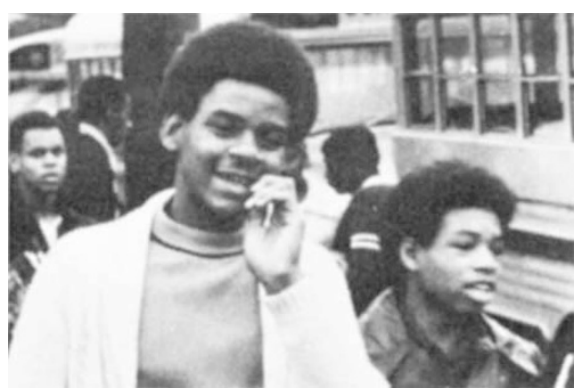

Black pupils: tests discriminate against them

Just what the ultimate effect of this ruling may be remains unclear. Despite the injunction, enrolment of blacks in mentally retarded classes remains disproportionately high. IQ tests can still be used to identify gifted children and those that qualify for some other special programmes. An appeal may be launched and related cases are pending in other parts of the country.

The case brought into full public view many of the problems related to IQ testing that have been argued about in scientific circles for many years. And there may be a growing sentiment in favour of paying more attention to "performance" rather than "ability". In an editorial following Peckham's decision, the San Jose Mercury suggested: "It would be far better for Larry $P$, and for students of every race, if educators would drop IQ tests entirely and rely instead on empirical evidence. Put the Larry $P$ 's in a regular classroom and see if they can handle the work. The time to move them into special programmes is after they have demonstrated an inability to keep up with their classmates."

John Douglas

\section{Dispute over Dow Chemicals' theory of dioxin traces} toxic chlorinated dibenzodioxins, released in November 1978, has been severely criticised by Professor Christopher Rappe of the University of Umea, Sweden. He says that the methodology used by Dow is poor, rendering some of the results questionable; and furthermore, the conclusions - that dioxins are ubiquitous and a natural consequence of combustion processes - are far from proven. They are not borne out by results from Rappe's own laboratory.

The report, on "The trace chemistries of fire", was prepared for the State of Michigan's Department of Natural Resources (DNR), after Dow found that fish taken from the Tittabawassee River contained measurable amounts of chlorinated dioxins and polychlorinated Michigan complex is discharged directly into the river and, not unnaturally, the company was assumed to be the source of the dioxins. Dow now dispute this charge: their report claims that dioxins are produced in many combustion processes, and are widespread. It has not convinced the DNR, however, which is insisting on additional measurements. Dr Robert Bumb, Director of Research at Dow's Michigan complex, believes that such additional tests would not only be expensive, but of little value; he says that other scientists are now confirming Dow's discovery.

Professor Rappe told Nature, however, that he disputes many of Dow's findings. Their discovery that dioxins are produced
A Dow Chemical Company report on the biphenyls. Effluent from Dow's huge

in commercial incinerators is not new, two independent European groups having reported earlier that the fly ash of municipal incinerators contains polychlorinated dibenzofurans. It was Dow's subsequent 'discovery' that chlorinated dioxins were present in the ash collected from other combustion processes which led them to develop their theory on the 'trace chemistries of fire'. Dow claim that dioxins are also present in ash collected from chemical tar burners, fossil-fuelled power plants, the 'mufflers' of automobiles and trucks, household chimneys, cigarettes and even charcoal-broiled steaks. There had to be a common factor to explain the wide occurrence and Dow developed the theory of the trace chemistries of fire - defined as 'numerous chemical reactions occuring during combustion at very low concentrations, parts per million and lower'. Yields from these reactions are very low, of the order of $10^{-9}$ per cent.

The company attributes the formation of chlorinated dioxins to the presence of dioxin building blocks, which would include chlorine and chlorinated aliphatic and aromatic hydrocarbons. Metals present may act as catalysts "in a sea of chemical reactivity including pyrolysis, oxidation, reduction and acidloysis'. In similar poetic vein, the report adds that in this sea, "ions, electrons, free radicals, free atoms and molecules form, combine and decompose'". Chlorinated dioxins, Dow suggests, must be formed in this process.

Not necessarily, says Rappe. His results, those of colleague Dr Hans Rudolf Buser, and of Dr Hans Paul Bosshardt of

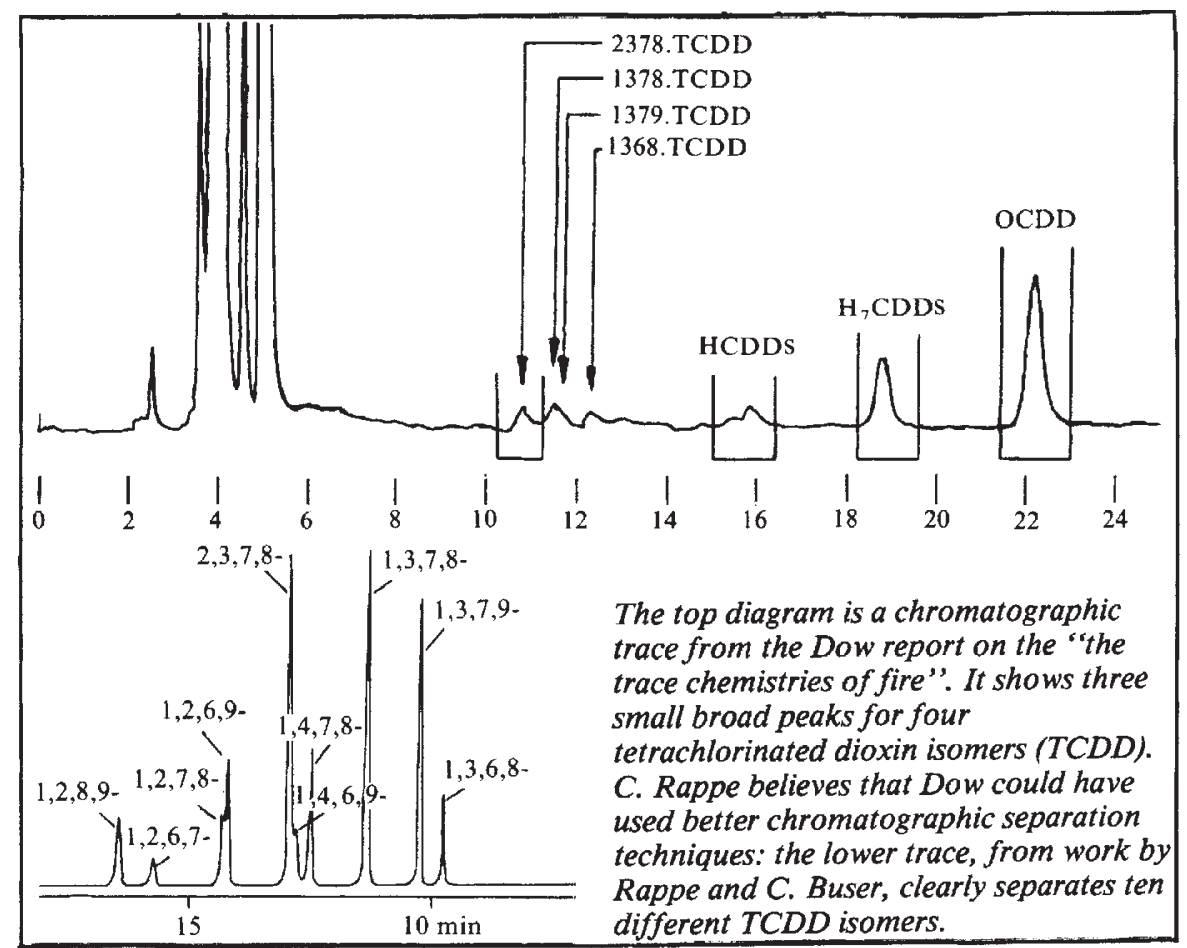

